\title{
IMPROVING DATA CONSISTENCY IN INDUSTRY 4.0: AN APPLICATION OF DIGITAL LEAN TO THE MAINTENANCE RECORD PROCESS
}

\author{
Francesco Longo $^{(a)}$, Letizia Nicoletti ${ }^{(b)}$, Antonio Padovano ${ }^{(c)}$, Agostino Bruzzone $^{(d)}$, Giovanni Mirabelli ${ }^{(e)}$, Adriano

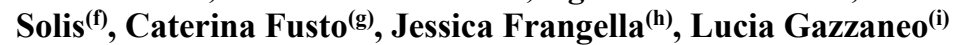

\author{
(a)(c)(e)(g)(h)(i) DIMEG, University of Calabria, Arcavacata di Rende (CS), Italy \\ (b)Cal-Tek S.r.l., Rende (CS), Italy \\ (d)DIME-University of Genoa, Italy \\ ${ }^{(\mathrm{f})}$ York University, Toronto (ON), Canada
}

\author{
(a)f.longo@unical.it, ${ }^{(b)}$ 1.nicoletti@cal-tek.eu, ${ }^{(\mathrm{c})}$ antonio.padovano@unical.it, ${ }^{(\mathrm{d})}$ agostino@itim.unige.it \\ ${ }^{(\mathrm{e})}$ giovanni.mirabelli@unical.it, ${ }^{(\mathrm{f})}$ asolis@yorku.ca, ${ }^{\mathrm{g})}$ caterina.fusto@unical.it, ${ }^{(\mathrm{h})}$ jessica.frangella@unical.it, \\ (i)lucia.gazzaneo@unical.it
}

\begin{abstract}
Being competitive in today's global business environment requires an even higher productivity, quality, flexibility and service levels in the perspective of the new era of industrial systems based on an augmented knowledge. As a result, many companies have focused their attention on better management of their asset and equipment. In this perspective, some factories have turned to Lean Management guidelines, while others, have tried to become "smart", following the principles of Industry 4.0 paradigm. Although a positive correlation has been established between them, the integration of lean practices and Industry 4.0 remains an open question that needs to be further explored and analyzed. The paper will give a contribute to the topic, investigating this relation within asset management perspective. In particular, a 4.0 solution will be used to evaluate if and to what extent Industry 4.0 is able to implement the lean principles of PokaYoke. The developed tool will prove its effectiveness in solving problems related to the maintenance record management of a firm.
\end{abstract}

Keywords: Industry 4.0; Digital Lean; Poka-Yoke; Asset Management; Maintenance

\section{INTRODUCTION}

The survival of a company on the market depends on its capability to satisfy customers' needs in a competitive way. Market forces such as globalization and customization have exacerbated this competition, retrieving industries attention to improving their performance. Increasing productivity, reducing costs, improving quality and service levels are some of the aspects that contribute to the purpose. In this perspective, some industries have turned to lean management guidelines, while others, have started to become "smart", following the principles of Industry 4.0 paradigm. Thus, the question of evaluating the relationship between the domains arose. As a matter of facts, a positive correlation has been identified (Sanders, et al., 2016) by virtue of the Industry 4.0's capability to implement the concept of "Jidoka" (that means "automation with a human touch" or "autonomation"). Nevertheless, integrating Lean Manufacturing and Industry 4.0 is a research field that needs to be further explored (Sanders, et al., 2016), evaluating the effects also in areas such as asset management which has proved to be of fundamental importance to improve the competitiveness of a company. Therefore, the paper aims to analyze the aspects of lean manufacturing and industry 4.0 relative to asset management activities. In particular, the article will integrate the lean methodology of Poka-Yoke and the technologies of Industry 4.0 in a 4.0 mistake proofing solution that will be used to modify the maintenance management process of a firm. The introduction of the tool will eliminate the errors that currently affect machine maintenance records and will facilitate performance analysis activities.

The article is organized as follows: section 2 presents a literature review; section 3 describes the methodology adopted; section 4 introduces the case study; Sections 5 summarizes findings and results.

\section{LITERATURE REVIEW}

The term Industry 4.0 describes the current development phase of Industry also called Fourth Industrial Revolution which has produced a new company dimension known as the "Cyber-PhysicalSystem" where real objects are enriched with a digital component. People and machines are interconnected, produce, share and use data that allows both to know the current situation of the system, foresee and analyze possible future scenarios and support decision making process. Industry 4.0 is the smart factories era whose advent is made possible by the so-called key enabling 
technologies such as simulation, big data and analytics, cloud, additive manufacturing and augmented reality.

Lean manufacturing stems from the Japanese industrial practices of Toyota Production System. It could be referred as a philosophy, a set of principles, a manufacturing paradigm that is adopted for separating the Value-Added Activities from the Non-Value-Added ones in order to identify "muda" (or wastes) caused by the latter. Lean implementation started in automotive industry, but soon its application extended to many other industrial sectors, including textile, construction, service, food and medical sectors (Bhamu \& Sangwan, 2014; Sundar, et al., 2014).

There are several tools and approach to implement lean principles whose selection depends on the purpose to be achieved. For instance, if the purpose is to eliminate defects caused by human, a good methodology is that of Poka-Yoke. Errors are eliminated by preventing, correcting or drawing attention to human errors as they occur, promoting the principles described in Table 1.

Poka-Yoke (or "mistake proofing") can take prevention or detection forms. Depending on the severity, frequency or downstream consequences, preventionbased mechanisms signal or halt processing when abnormalities are about to happen. The detection-based forms, instead, are used when is not possible or economically feasible to prevent defects. Poka-Yoke should be simple objects and devices used all the time by all the operators where mistakes occur in order to cheaply eliminate defects. Each approach is achieved through a specific method. In particular, the detection form of Poka-Yoke can use the contact-method, which tests the characteristics of a product in order to identify a defect; the fixed value-method which ensures that all parts of a product are available in the right quantities; and the motion-step-method, which ensures that the activities needed to obtain an output are performed in the right number and sequence (Malega, 2018).

Table 1: Basic principles of Poka-Yoke

\begin{tabular}{ccc}
\hline Principle & Objective & Way \\
\hline Elimination & $\begin{array}{c}\text { Eliminating the } \\
\text { possibility of error } \\
\text { Replacing the } \\
\text { process with a more } \\
\text { reliable one } \\
\text { Making the work } \\
\text { Facilitation }\end{array}$ & $\begin{array}{c}\text { Redesigning the } \\
\text { process/product } \\
\text { Using automation }\end{array}$ \\
Detection & $\begin{array}{c}\text { Detecting the error } \\
\text { before further } \\
\text { processing }\end{array}$ & $\begin{array}{c}\text { Developing } \\
\text { software which } \\
\text { notifies a worker } \\
\text { when a wrong } \\
\text { input is made }\end{array}$ \\
\hline
\end{tabular}

Both Industry 4.0 and Lean Manufacturing aim to increase flexibility and productivity of a firm. While Lean is a well-established methodology, Industry 4.0 is a relatively new paradigm, thus there is a shortage of studies exploring their link (Buer, et al., 2018). Nevertheless, a positive relationship has been identified (Sanders, et al., 2016). In particular, the technologies and concepts of the Fourth Industrial Revolution seem to act as enablers of Lean dimensions, increasing the technical feasibility and the related benefits. For instance, by producing Smart Products and giving the possibility to collect and analyze a huge amount of data, Industry 4.0 allows a strong involvement and integration of customers in the business process where the data collected are used to anticipate their needs and can be instantaneously shared along the entire supply chain; while the use of tags and wireless tracking promotes JIT delivery of goods by suppliers. As regards Asset Management, the most obvious implications concern maintenance operations. Indeed, data collection, data interchange and (big) data analysis of CPS support the principles of Total Productive Maintenance, including monitoring and improvement of the Global Plant Efficiency, development of autonomous preventive maintenance and predictive maintenance. On the other hand, Augmented Reality has proven a great potential for maintenance operations, providing augmented contents on one side and enriching maintenance experience on the other side. The classic lean tools are changing as well. As a matter of facts, there are many empirical applications showing how Lean tools are losing some of their initial edge (Behrendt et al., 2017). Striking examples are that of Virtual Kanban used to replace physical cards for orderoriented production control and inventory control (Filho \& Lage, 2010) or the iBin System for Kanban bins where a camera is used to detect the charging level of the bin and the iBin reports the information to the inventory control system and automatically sends order to suppliers (Würth Industrie Service $\mathrm{GmbH} \& \mathrm{Co}$. KG, 2013).

The implementation of lean principles through Industry 4.0 technologies offers many opportunities, but also challenges. Indeed, rush in automation without analyzing and identifying the sources of wastes will led to digitize inefficiencies (Nafais, 2017). In a nutshell, while lean approach could be seen as the lynchpin of operational improvements, process standardization, and promotion of kaizen, Industry 4.0 should be seen as a provider of advanced technologies and solutions that are selected and adopted to implement the lean guidelines. In this perspective "Industry 4.0 is just the topping on the cake" (Rüttimann \& Stöckli, 2016).

\section{METHODOLOGY}

In order to achieve the aims of this study, the traditional maintenance process in manufacturing industries has been analyzed. The current process has been then redesigned by introducing an ad-hoc tool integrating Industry 4.0 key enabling technologies and Lean manufacturing principles, i.e. the Poka-Yoke practice. 
The developed mobile application is presented and later deployed in an industrial case study.

\subsection{Initial maintenance management process}

In order to identify the underlying reasons of the problem, a traditional maintenance process in manufacturing industries has been analyzed. The maintenance process usually involves three different actors: the operator, the Head of Maintenance and the Maintenance operator. Maintenance operations are also frequently outsourced; thus, both the Head Maintenance and the Maintenance Operator are external to the company. When an abnormality or a failure occurs (e.g. vibration of the axis, head locking, refrigerant leakage, etc.) the asset puts out a signal. The operator is in charge of detecting the signal and filling a maintenance job request. In particular, he fills the request manually, entering on a sheet the following information: plant location, identification number of the maintenance job request, alarm code, the description of the alarm code, the description and the details of the alarm, the ID of the asset, the location of the asset, the signalman's ID, and the reporting date. The sheet constitutes the maintenance record of the asset. Once completed the filling, he sends a copy of this maintenance job request to the head of maintenance. The head of maintenance takes the request in charge, analyses it and, considering also the maintenance orders previously scheduled, draws-up and updates the maintenance plan. According to the scheduled interventions, a maintenance operator will perform the maintenance operations. Hereafter, the Head of Maintenance will check if the cause of the alarm has been solved (eventually, a second intervention could be rescheduled). Both the Head of Maintenance and the maintenance operator are required to fill the remaining fields of the maintenance record. In particular, the Head of Maintenance will enter the references of maintenance operators (ID and name), the expected starting and closing dates for maintenance operations, and the check period, while maintenance operator will enter the information about the effective starting and closing dates. The entire process is resumed in Figure 3.

Due to the manual filling of maintenance records carried out by the maintenance personnel, a high delay in managing breakdowns or alarms occurs. Furthermore, since the data are not structured and incomplete, this slows down the process. In particular, the data inconsistency errors can be classified as follow:

1. data are incomplete;

2. data are affected by typos;

3. the terminology used to describe the same type of error is not uniform.

The consequences of maintenance data inconsistency errors are the following:

1. there are no records of a performed maintenance task or of an executed intervention on machines;
2. it is not possible to trace back to the person in charge of a maintenance track or the person who performed maintenance tasks;

3. it is not possible to evaluate delays with respect to the maintenance plan;

4. it is not possible to analyze and improve the maintenance process or to assess the performance of the third-party company in charge of the maintenance activities.

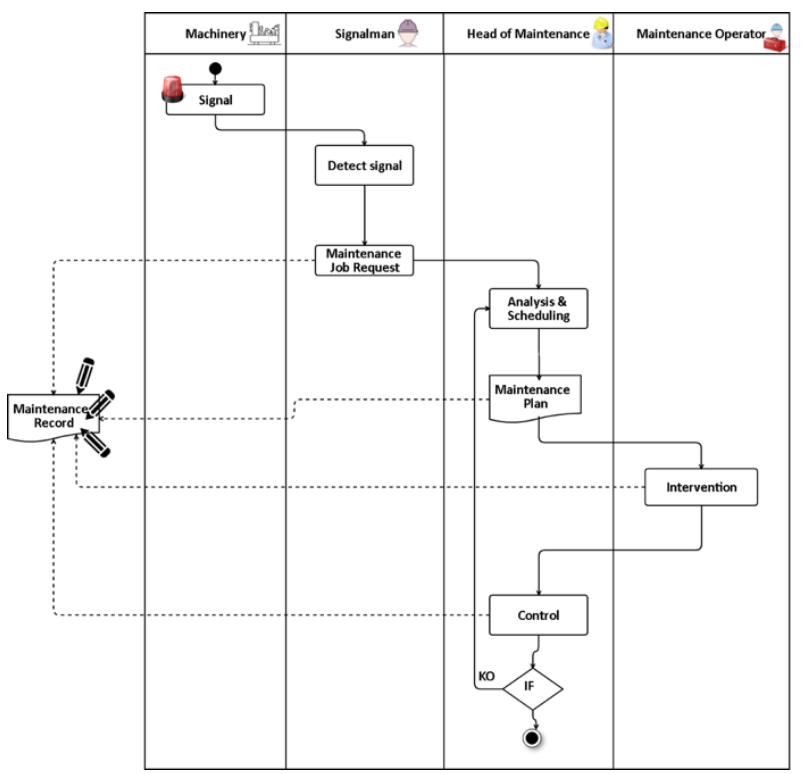

Figure 1: The initial maintenance management process

\subsection{An Industry 4.0 driven Poka-Yoke approach}

The above described process can benefit from an Industry 4.0 driven Poka-Yoke approach, which is aimed at solving data inconsistency errors in maintenance. The process can be indeed re-designed as in Figure 4. Once a signal has been notified by an equipment, the signalman is in charge to detect it and fill a job request. The operator will be allowed to send the job request to maintenance office if and only if he will complete all the required fields. By scanning a QR code or by selecting the machine among the list of the available ones, the operator will identify the machine where the failure has occurred. All the information about the machinery (e.g. plant, location, production orders) will be automatically reported on the job request. Then, the signalman will be required to select (or insert) the alarm code notified by the machine. Once again, the description of the error will be automatically reported on the job request. The operator will be allowed to send the job request only when the two fields (alarm code and machinery ID) will be filled. Once received the request, the head of maintenance will prepare the maintenance plan. The order will be not saved and notified until the required fields (e.g. estimated times and dates, maintenance operator reference). Similar considerations can be made with 
respect to the remaining operations (maintenance intervention and equipment control).

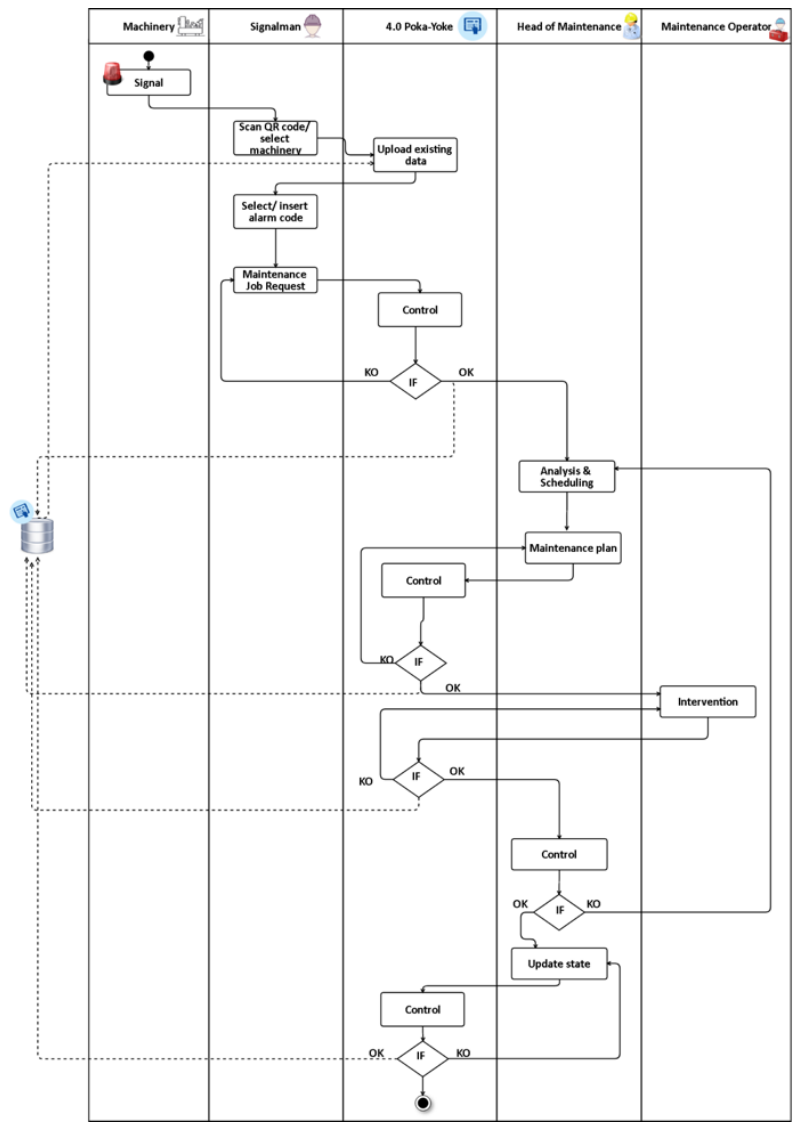

Figure 2: The maintenance management process after the introduction of the 4.0 Poka-Yoke

\subsection{A new 4.0 application to implement Poka-Yoke in the maintenance process}

A new 4.0 application to implement Poka-Yoke in the maintenance process has been developed. It uses the Industry 4.0 technologies on one hand, embedding and implementing the Poka-Yoke tenets on the other. Basically, the solution allows Knowledge creation and Knowledge Management. the architecture of the system could be described as the set of two collaborative parts: the contents manager and the contents user. The former, cloud-based, provides a series of functionalities for implementing the contents, the data and metadata (e.g. name, ID, description, $\mathrm{QR}$ code, 3D model, AR contents, etc.as shown) related to a particular object (e.g. a plant or an equipment) as shown in Figure 1, while the latter allows to access data and contents and to enter data as well, as shown in Figure 2. The underlying architecture is developed by using the Laravel framework and includes a relational MySQL DB, the Java-based Apache Solr open source research framework (containing a non-relational database) that uses the Lucene Java search library for full text search and indexing; HTTP / XML APIs (e.g. REST and JSON) for data search. The system is provided on web/mobile applications that make the platform easy to use.

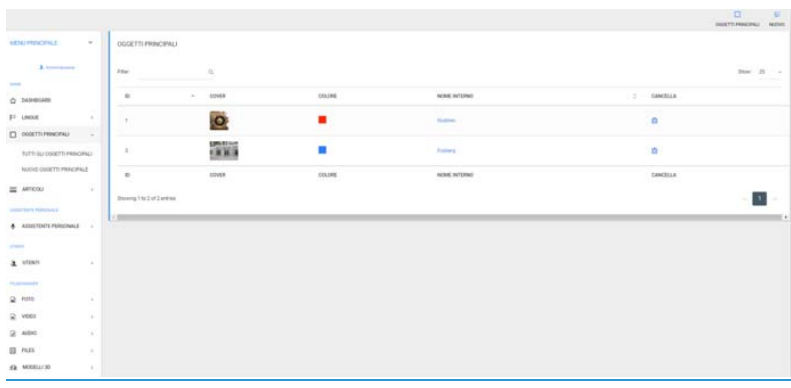

Figure 3: Contents creation

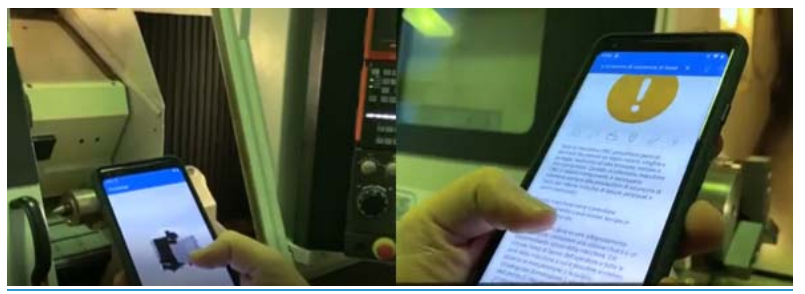

Figure 4: Contents fruition

The capability of the solution to implement the principles of Poka-Yoke has been tested within maintenance process of a firm. To this end, the maintenance process of the company has been evaluated and formalized through the use of flow charts. Then, the maintenance records collected by maintenance personnel have been analyzed allowing to reveal problems in data consistency due to the manual filling of records performed by operators. The solution has been customized to address these problems, entering the objects needed to prevent errors (such as alarm codes, machineries ID and operators ID). Finally, this application has been deployed into a real industrial environment and changes introduced by poka-yoke in the maintenance process and in maintenance records have been analyzed.

\subsection{Case study}

The application study involved an enterprise that is active in the Oil \& Gas industry and produces heat exchangers. Currently, the company pursues two maintenance strategies: corrective maintenance and preventive maintenance. The former is performed when assets break down. The latter is performed to lessen the likelihood of equipment failing. Preventive maintenance is performed while the equipment is still working; it can be scheduled on a time or usage-based trigger. Actually, there is a substantial difference between the moment when a failure or a problem has been detected and the moment when the problem is solved, and this causes wastes and delays on product delivery. Additionally, the company is not aware whether excessive preventive maintenance is performed, whether the adopted maintenance intervals could be reduced or increased. Finally, the enterprise can't easily carry out analysis of performance. 


\section{RESULTS AND DISCUSSION}

Analyzing the data collected during the period June 2017 until June 2018 in the company under study, it has been noticed that the delay in maintenance scheduling is attributable to the manual filling of maintenance records carried out by the maintenance personnel and the data kept therein. Indeed, the scheduling is based on the analysis of information included in the maintenance records and, since the data are not structured and incomplete, this slow down the process. Considering the "closed" maintenance orders and assuming that the expected start dates coincide with the effective dates when maintenance operations are performed, it is possible to observe how on 758 maintenance job requests, the $43 \%$ has been turned to maintenance orders between 12 and 15 months, while the remaining $57 \%$ between 6 and 12 months. Considering the average case, the total time required to schedule the maintenance orders could be estimated as a percentage of the time required to turn the maintenance job requests in maintenance orders. Assuming a percentage of $10 \%$, the total time required to schedule the maintenance orders is 1 month. This time is due to the errors that affect data.

Using the data inconsistency categories to characterize the data collected during the reference time, the errors made by the operators have been classified as shown in Table 2 .

Table 2: Errors performed by the signalman

\begin{tabular}{cccc}
\hline & $\begin{array}{c}\text { Missing } \\
\text { Data }\end{array}$ & Typos & $\begin{array}{c}\text { Heterogeneous } \\
\text { Terminology }\end{array}$ \\
\hline Plant & $0,26 \%$ & $5 \%$ & $0 \%$ \\
$\begin{array}{c}\text { Maintenance } \\
\text { Job Request } \\
\text { ID }\end{array}$ & $0,13 \%$ & $3 \%$ & $0 \%$ \\
$\begin{array}{c}\text { Alarm code } \\
\text { Alarm } \\
\text { description } \\
\text { Signalman } \\
\text { ID }\end{array}$ & $0,13 \%$ & $65 \%$ & $40 \%$ \\
$\begin{array}{c}\text { Signalman's } \\
\text { name }\end{array}$ & $43,27 \%$ & $10 \%$ & $0 \%$ \\
$\begin{array}{c}\text { Reporting } \\
\text { date }\end{array}$ & $0,78 \%$ & $13 \%$ & $10 \%$ \\
\hline
\end{tabular}

The alarm code that allows to identify the root causes of the problem, the resource to use and the solution to be adopted, lacks $99 \%$ of the time. From the other hand, the description that could replace the use of the alarm code is affected by typos $(65 \%)$ or the same problem is described in different ways.

Moving the attention on analysis of performance, it is affected by the same problems. Over the errors performed by the internal operators, the ones performed by the maintenance officers are noticed (Table 3 and Table 4). For instance, the expected start and end dates lack the $90,5 \%$ of times, as well as the information related to the maintenance operator lacks the $43,27 \%$ of time.

Table 3: Errors performed by the head of maintenance

\begin{tabular}{cccc}
\hline & $\begin{array}{c}\text { Missing } \\
\text { Data }\end{array}$ & Typos & $\begin{array}{c}\text { Heterogeneous } \\
\text { Terminology }\end{array}$ \\
\hline $\begin{array}{c}\text { Maintenance } \\
\text { Job Order } \\
\text { ID }\end{array}$ & $90,5 \%$ & $10 \%$ & $0 \%$ \\
$\begin{array}{c}\text { State of the } \\
\text { Order }\end{array}$ & $0,26 \%$ & $30 \%$ & $0 \%$ \\
$\begin{array}{c}\text { Maintenance } \\
\text { Operator ID }\end{array}$ & $43,27 \%$ & $10 \%$ & $0 \%$ \\
$\begin{array}{c}\text { Maintenance } \\
\text { Operator } \\
\text { name }\end{array}$ & $43,27 \%$ & $10 \%$ & $0 \%$ \\
$\begin{array}{c}\text { Expected } \\
\text { start time }\end{array}$ & $67,15 \%$ & $0 \%$ & $0 \%$ \\
$\begin{array}{c}\text { Expected } \\
\text { end time }\end{array}$ & $65,3 \%$ & $10 \%$ & $0 \%$ \\
\hline $\begin{array}{c}\text { Expected } \\
\text { start day }\end{array}$ & $90,5 \%$ & $12 \%$ & $19 \%$ \\
\hline $\begin{array}{c}\text { Expected } \\
\text { end day }\end{array}$ & $90,5 \%$ & $10 \%$ & $23 \%$ \\
$\begin{array}{c}\text { Check } \\
\text { period }\end{array}$ & $0,26 \%$ & $7 \%$ & $23 \%$ \\
\hline
\end{tabular}

Table 4: Errors performed by the maintenance operator

\begin{tabular}{cccc}
\hline & $\begin{array}{c}\text { Missing } \\
\text { Data }\end{array}$ & Typos & $\begin{array}{c}\text { Heterogeneous } \\
\text { Terminology }\end{array}$ \\
\hline $\begin{array}{c}\text { Effective } \\
\text { start time }\end{array}$ & $90,5 \%$ & $7 \%$ & $3 \%$ \\
\hline $\begin{array}{c}\text { Effective } \\
\text { end time }\end{array}$ & $90,5 \%$ & $2 \%$ & $0 \%$ \\
$\begin{array}{c}\text { Effective } \\
\text { start day }\end{array}$ & $12,8 \%$ & $10 \%$ & $15 \%$ \\
$\begin{array}{c}\text { Effective } \\
\text { end day }\end{array}$ & $12,93 \%$ & $14 \%$ & $20 \%$ \\
\hline
\end{tabular}

The following observation can be done.

1. The 4.0 tool could be described as a process standardization that embeds and implements the elimination, replacement and facilitation principles of Poka-Yoke. Indeed, by substituting the sheet with the application, the possibility of make error has been eliminated.

2. By inserting check points on data structure and completeness and providing a list of predefined information, the possibility to have unstructured or missing data has been avoided. Thus, the process is more reliable.

3. In addition, it is possible to say that the process has been facilitated. Indeed, having a digital DB with structured and integral data instead of sheets, allows head of maintenance to schedule 
more quickly the maintenance orders and plans. The previously estimated time (e.g. 1 month) has been eliminated. This means providing a better level of service to the customer. On the other hand, the possibility to have data aligned and updated between parts, allows firm to perform evaluation both on the plants and maintenance personnel.

The 4.0 tool assumes the prevention form of PokaYoke. As stated before, the structure prevents all the human errors resumed in Table 2, Table 3 and Table 4. It implements the motion-step method, because ensure that all the activities necessary to fill the maintenance records will be performed by personnel.

\section{CONCLUSIONS AND FURTHER RESEARCH}

Issues related to the collection, use and store of accurate and reliable data are currently very common among industries (Christiansen, 2018). The proposed paper discusses about the relationship between Industry 4.0 and Lean Manufacturing within Asset Management area. Since Lean Principles should shape the relation, the lean methodology of Poka-Yoke has been selected and a 4.0 solution has been implemented. The ability of the solution to embed and implement the lean tenets and provide clear benefits to the maintenance process has been evaluated in a firm operating the Oil \& Gas industry. Further research will be devoted to assess the impact of the developed tool on the firm's productivity, to integrate the tool with other company management systems and extend its use to other processes.

\section{REFERENCES}

Alkhoraif, A., Rashidb, H. \& McLaughlin, P., s.d. Lean implementation in small and medium enterprises: Literature review. Operation Research Perspectives, Issue https://doi.org/10.1016/j.orp.2018.100089.

Bhamu, J. \& Sangwan, K. S., 2014. Lean manufacturing: Literature review and research issue. International Journal of Operations \& Production Management, July, pp. 876-940.

Buer, S.-V., Strandhagen, J. O. \& Chan, F. T. S., 2018. The link between Industry 4.0 and lean manufacturing: mapping current research and establishing a research agenda. The International Journal of production Research, 56(4), pp. 1-17.

Christiansen, B., 2018. 4 Biggest Building Maintenance Challenges and Solutions.

Filho, G. \& Lage, J. M., 2010. Variations of the kanban system: literature review and classification. Int $\mathbf{J}$ Prod Econ, Volume 125, p. 13-21.

Malega, P., 2018. Poka-Yoke - solution to human errors in the production process. The International Journal of Business Management and Technology, 2(5), pp. 207-213.

Nafais, S., 2017. Manufacturing, Automated Lean. Kingston University London.

Rüttimann, B. G. \& Stöckli, M. T., 2016. Lean and Industry 4.0-Twins, Partners, or Contenders? A
Due Clarification Regarding the Supposed Clash of Two Production Systems. Journal of Service Science and Management, Volume 9, pp. 485-500.

Sanders, A., Elangeswaran, C. \& Wulfsberg, J. P., 2016. Industry 4.0 implies lean manufacturing: Research activities in industry 4.0 function as enablers for lean manufacturing. Journal of Industrial Engineering and Management (JIEM), 9(3), pp. 811-833.

Shrimali, A. K. \& Soni, K. V., 2017. A Review on Issue of Lean manufacturing Implementation by Small and Medium Enterprises. International Journal of Mechanical and Production Engineering Research and Development, 7(3), pp. 283-300.

Sundar, R., Balaji, A. N. \& SatheeshKumar, R. M., 2014. A Review on Lean Manufacturing Implementation Techniques. Procedia Engineering, 97(12th GCMM), pp. 1875-1885.

Würth Industrie Service GmbH \& Co. KG, 2013. $\mathrm{iBin}(\mathrm{R})$ stocks in focus - the first intelligent bin 